\title{
Turismo, natureza e história ambiental: chácaras de lazer na represa de Capivara- $P R$
}

\author{
Tourism, nature and environmental history: leisure farms on \\ the banks of the Capivara Dam.
}

\section{Gilmar Arruda ${ }^{1}$}

\section{RESUMO}

Segundo dados da Organização Mundial de Turismo o número de viagens internacionais ao redor do mundo, no ano de 2012, superou a marca de 1 bilhão, das quais, mais da metade, tinham como motivo da viagem o turismo. Entre os destinos das "viagens de férias" estão, a praia, o campo, as reservas naturais, etc. Determinadas formas de percepção e/ou representação do natural atraem os turistas para essas áreas. Esse texto expõe a construção de uma temática, a relação entre turismo e natureza, a partir de um estudo de caso: as chácaras de lazer às margens da represa de Capivara, rio Paranapanema, região norte do Estado do Paraná.

Palavras-chave: História ambiental. Natureza. Turismo. Casas secundárias. Tempos livres.

\section{ABSTRACT}

According to the World Tourism Organization the number of international travels, in 2012, around the world surpassed 1 billion, of which more than half had as purpose of travel tourism. Among the targets of the 'holiday trips "are the beach, the countryside, nature reserves, etc.. Certain forms of perception and / or representation of natural attract tourists to these areas. This text exposes the construction of a theme, the relationship between tourism and nature, from a case study: the leisure farms on the banks of the Capivara Dam, Paranapanema River, north of the state of Paraná.

Keyword: Environmental History. Nature. Tourism. Second homes. Free times.

1 Doutor em História - Unesp - Assis(1997). Professor Departamento de História, Universidade Estadual de Londrina, Pesquisador-Bolsista do CNPq. Investigador externo do CITCEM-Universidade do Porto. Posdoutorando no CESUniversidade de Coimbra. Publicou e organizou vários livros como: Cidades e Sertões (2000); Natureza, territórios e imagens (2005) e A natureza dos rios (2008) e História ambiental no sul do Brasil: apropriações e representações (2012). 


\section{1 - O turismo, os tempos livres e os tempos sociais}

Sair de férias significa o desejo de viajar: duas expressões que estão, atualmente, intimamente e inseparavelmente associadas. Férias, práticas de um tempo livre, de não trabalho. O tempo livre só passou a ter sentido quando o tempo do trabalho linear e cronometrado tornou-se uma realidade em fins do século XIX no mundo urbano-industrial. Mas das concessões de tempo livre até o reconhecimento como direito a 'férias pagas' haveria de se passar ainda cerca de cinco décadas. Somente pós-segunda guerra mundial essa prática tornou-se amplamente reconhecida e atribuída na maioria dos países ocidentais. Se o tempo livre, as férias pagas, tornou-se uma realidade, como então, foram usados os tempos livres? As antigas práticas de preenchimento do tempo da nobreza, o Grand Tour, do século XVIII e XIX, gradualmente foram sendo incorporadas e transformadas em práticas de massa, de uma indústria de massa. Não demoraria muito para surgir uma economia, bem como desejos e projetos de controle do tempo livre das classes populares, transformando o tempo livre em tempo-mercadoria: "O Fim da Segunda Guerra mundial constituiu uma ruptura igualmente evidente. A seguir à vitória dos Aliados triunfa um lazer-mercadoria entendido como um tempo disponível para consumo."(CORBIN, 2001, p.07). Inaugura-se a sociedade do lazer, do lazer-consumo, na qual está inserida a prática da viagem de férias.

Algumas das motivações do turismo podem ter sido originadas na revolução burguesa, com sua nova 'consciência de liberdade' dos indivíduos, oriunda da própria sociedade da qual a revolução brotara. A nova situação não implantou uma 'homogeneidade social', como muitos almejaram, mas apenas criou uma 'homogeneidade espacial', percebida especialmente com os avanços tecnológicos, como a ferrovia e navegação a vapor que permitiram a uniformização dos tempos de deslocamento de homens e das mercadorias ao redor do mundo.(ENZENBERGER, 1985, p.213). Mas o desejo de liberdade, que permitiu a burguesia reivindicar direitos, foi sendo limitado com a expansão do processo de produção capitalista, até se constituir apenas como um desejo de evasão, repetido e reiterado pelas campanhas e políticas sobre o turismo:

...até que ela se cristalizou espacialmente na imagem da natureza distante da civilização, temporalmente na imagem da história passada, tornando-se folclores e monumento. Estas, a paisagem intocada e a histórica intocada, são as imagens-guia do turismo até hoje."(idem, p.214) 
O imaginário sobre as ferrovias reflete essa pulsão de evasão, configurado no desejo de 'fuga da realidade' para locais distantes e exóticos, para além do lugar de trabalho, como um “...intenso desejo de escapar dos locais de moradia e trabalho da revolução industrial." Mas a liberdade, como vitória da burguesia, mesmo que restrita ao desejo de evasão, ainda assim, seria apropriada por todos: "A liberdade que pareciam [os burgueses] ter conquistado nas rochas das montanhas de Berna, no gelo das calotas polares, nas selvas equatorianas, em breve seria exigida por todos como um novo direito humano."(idem, p. 216). Rapidamente, o novo direito humano, que tinha assumido '...os traços inofensivos de uma viagem de férias' foi incorporado na máquina capitalista, constituindo-se nas origens da 'moderna' indústria do turismo: “...há muito a nostalgia de distância e liberdade fora dominada pela sociedade da qual emanara. A libertação do mundo industrial estabelecera-se ela mesma como indústria, a viagem para fora do mundo do comércio transformara-se ela própria em mercadoria."(idem, p. 218).

A viagem de férias, inserida no turismo de massa, tornava-se assim, em uma mercadoria que, como as outras mercadorias, necessita de um sistema de produção: regras, montagem, fabricação em série e consumo. Uma nova mercadoria, ainda que imaterial, uma mercadoria fictícia, no sentido de Karl Polanyi, mas ainda assim uma mercadoria. $O$ turismo, inicialmente uma atividade da nobreza, o Grand Tour, viagem que os jovens aristocratas faziam pelo continente com o intuito de 'aprender' e, na volta, tornavam-se gentlemans. "The Tour, fenômeno original, nasceu e se desenvolveu na Inglaterra do século 18 que fez toda as Revoluções: industrial, agrícola, financeira. Acrescentemos a Revolução Turística... (BOYER, 2003, p.39)

No tempo social no qual se passava a vida da nobreza não existia um corte profundo entre tempo de trabalho e tempo livre. As atividades que hoje são nomeadas de turismo estavam inseridas na ideia de recreação, não era turismo, nem lazer. Era uma forma de se 'preencher' o tempo: "Ter tempo para recrear-se ou instruir-se em viagem é, repetindo, um dos privilégios da nobreza." (CAMARGO, 2007, p. 100)

O turismo, atualmente, é resultado da imitação que a burguesia, já com bens acumulados e tempo suficiente para gastar, fez das práticas da nobreza. Mas até o final do século XIX, foi uma atividade de elite, restrita. É certo, porém, que os tempos livres, e posteriormente as férias pagas, ampliavam-se cada vez mais, em especial na Inglaterra, onde cerca de 1 milhão de trabalhadores manuais usufruíam das férias pagas no início da década de 1920. (PORTER, 2001, p.27). Julia Csergo menciona que a exposição de Paris, em 1900, teria recebido 50 milhões de visitantes.(2001, p.200). ${ }^{2}$ A viagem de férias em massa, destinada aos trabalhadores, ampliou-se muito nos anos de 1930, em especial na Alemanha, através da organização estatal Kraft durch Freude (A força pela Alegria): "Em 1937, a Kraft

2 Não há referência no texto de Julia Csergo de como foi calculado esse número. Em todo caso, a se concordar com ele, seriam mais de 100.000 visitantes por dia. Convém tomar esse número com certa cautela. 
durch Freunde organizou trinta e sete mil viagens que abrangeram oito milhões e duzentos mil vereantes e turistas. A principal forma de deslocação continuava a ser a excursão de fim de semana(passeio pedestre, circuito em autocarro ou comboio)." (RICHES E STRAUS, 2001, p.479). Já, depois da segunda guerra, a realidade havia mudado:

No início dos sessenta os operários franceses não se contavam entre os que menos partiam. No conjunto de todas as classes, a França ia à frente, com 37,5\% de partidas (em 1961) da Alemanha ocidental (31\% em 1959 ) e da Itália (13\% em 1959); mas ia muito atrasada relativamente aos Países Baixos (45\% em 1961), à Bélgica (48\% em 1959), ao Reino Unido (58\% em 1961) à Suécia (72\% em 1961). Dos vinte milhões de franceses que então iam de férias, sete milhões eram operários.(idem, p.493).

Essas estatísticas demonstram as relações existentes entre as férias pagas e a ampliação das viagens de férias. Portanto, somente com a expansão, regulação, concessão e ampliação mais universal de um tempo livre, na qual as férias foram inventadas, teria ocorrido o surgimento do turismo de massa, como se dá atualmente, o tempo da viagem:

Quanto à importância do próprio turismo hoje, no contexto do conceito de tempo social, creio que ele vive e se manifesta atualmente na divisão internalizada do tempo de férias, ou das férias. Refiro-me ao fato de planejarmos as férias de hoje sempre em cotejo às anteriores, ignorando ou omitindo o tempo de trabalho que as antecede, fazendo um corte nessa sequencia linear e, estabelecendo para esse tempo, no tempo do não-trabalho, um nicho separado e internalizado.(CAMARGO, 2007, p. 12)

A divisão entre o tempo livre e o tempo de trabalho se afirmou no mundo urbanoindustrial, no qual o tempo passou a ser concebido e vivenciado segundo uma divisão produzida historicamente, "Em outras palavras, o tempo passou a ser comprado, vendido e negociado de múltiplas formas, tal qual uma mercadoria”.(SANT'ANNA, 1992, p.15). Mas existe uma diferença entre tempo livre e tempo de lazer. A associação não é imediata entre a expansão dos tempos livres aos operários e o seu uso em forma de viagem de lazer e turismo. Essa associação só se estabeleceria após a segunda grande guerra. (CORBAIN, 2001)

A viagem como lazer é um fenômeno, portanto, associado à expansão do tempo livre e das férias pagas, evidenciado nas sociedades industrializadas e urbanizadas. Já as transformações internas das práticas do turismo parecem seguir um padrão de invenção e imitação. Invenção com finalidade de distinção. A mudança fundamental ocorrida no século XX teria sido na difusão: "Por muito tempo ela se fez somente pela imitação através das altas camadas da Sociedade, os que eram chamados de 'o mundo'. Imitação capilar, pois cada 
estrato copiava os comportamentos e as escolhas da categoria imediatamente superior." (BOYER, 2003, p. 32). Mesmo sendo, atualmente, um fenômeno de massa, com ampla participação de diversas classes sociais, quando considerado como lazer ele ainda é restrito:

O cinema, a televisão, a publicidade atualmente fazem um número cada vez maior de pessoas partir... Mas continuamos muito abaixo dos quase $100 \%$ que caracterizam a televisão, o rádio, a audição de cassetes, práticas maciças, ao passo que as férias atingem, na melhor das hipóteses, 60 a $70 \%$ da população.(idem, p. 34).

O turismo também é influenciado por discursos de especialistas. No século XIX, o discurso médico influenciou o termalismo e a vilegiatura marinha, promovendo a expansão das estações de água e dos balneários. (RAUCH, 2011; BOYER, 2003; CAMARGO, 2007 e SCHOSSLER, 2010). Outros discursos influenciaram essas práticas no século $\mathrm{XX}$, como o discurso ecológico:

\begin{abstract}
Os turistas de massa eram percebidos como consumidores da Natureza, devoradores de paisagens. A onda ecológica pós-1968 deu uma tonalidade - o verde - e uma exigência a este amor pela Natureza; a preocupação em preservar e proteger tem fundamentos bem mais antigos.(BOYER, 2003, p.55).
\end{abstract}

Tanto a procura do campo, o sentido da oposição campo x cidade, como a sensibilidade moderna sobre a natureza possuem raízes no século XVIII e XIX.(THOMAZ, 1998, ARRUDA, 2000) As cidades tidas como lugar de civilização e progresso passaram, gradualmente, a serem percebidas como Babilônia, poluição, lugar da perdição, enquanto o campo se transformava em refúgio, refrigério, harmônico, natural. Assim também a natureza, ameaçadora, transformada em campo produtivo, foi depois imaginada para ser preservada em sua originalidade, ou transformada em parques. (DIEGUES, 1996, THOMAZ, 1988; WILLIANS, 1990, BOYER, 2003). Após a segunda guerra mundial surgiria o que Donald Worster denominou de a "era da ecologia". Nesse período emergiu o tom do verde, a necessidade de proteção, de retorno à natureza, a preocupação de preserva-la e protege-la, pois estaria ameaçada pelos humanos. (WORSTER, 1996, MCORMICK, 1992). Esse movimento tornou a ecologia, enquanto discurso, influente nos tempos contemporâneos, condicionando quase todas as falas das sociedades. (BARBOSA, 1991). O termo ecologia já havia, no início da década de 1990, assumido um caráter de valor, de discurso político: 
Podemos dizer, hoje, que falar da (do lugar da) ecologia - ao denunciar agressões ao meio ambiente, ao se mostrar consciente dos problemas ambientais globais e/ou se mostrar atuando de acordo com uma postura ecológica, etc. - é estar se colocando dentro do espaço de significação política.(SILVA, 1997, p.142).

Além de ter-se tornado um discurso político, valorizando ou desvalorizando os artefatos, as práticas e as ações sociais, também marcaria novas atitudes, ou novas práticas do turismo, evidenciadas pela expansão da sua vertente nomeada como ecológico. Esse movimento atenderia a desejos contemporâneos de retorno à natureza, de sua proteção, ou mesmo de uma "...tentativa quase literal de reencontrar a natureza por meio do turismo, especialmente sua variação 'ecológica' ou 'ambiental'. (SERRANO, 1997, p. 11).

Convém ressalvar que o interesse pelo mundo natural, pela prática do turismo, não é originário da 'era da ecologia'. Desde o século XIX pode-se encontrar a procura por lugares junto à natureza, para o termalismo, como estâncias de águas, para a pesca, o alpinismo, para caça, para caminhadas e, por fim, para a vilegiatura. A praia, nesse sentido, é um dos locais naturais que desde o século XVIII vem sendo alvo de discursos incentivando a sua procura. Inicia-se com os discursos médicos até alcançar, no mundo contemporâneo, o hedonismo do sol e dos corpos bronzeados. Esse fenômeno da praia é recorrente ao redor do mundo. (CORBIN, 1989, CACOPARDO \& ZUPPA, 2005, SCHOSSLER, 2010, MARTINS, 2011) O sentido de natural envolve, portanto, uma ampla gama de significados, não se restringindo aos construídos após a 'era da ecologia'.'

Além da influência dos discursos e sentidos do natural, o turismo de massa contemporâneo possuiria um caráter sazonal, motivada pela obrigação das datas de férias, os finais de semana e feriados prolongados. Apresentaria, também, uma característica de migração em massa das cidades, como o esvaziamento urbano em tempo de verão, rumo ao campo ou a praia. Seria, para Marcos Boyer, uma revanche do movimento centrípeto do século 19, do êxodo rural em direção as cidades, que poderia levar a interpretar esse fenômeno como 'saudades da ruralidade', lembranças da infância no campo, das raízes camponesas, pelo menos para parte do mundo europeu: "Isto é verdadeiro, na primeira metade do século 20, para boa parte da burguesia.(...) Mas não é mais verdadeiro atualmente para a maioria dos urbanos, citadinos há várias gerações, ignorantes sobre a vida rural em seu conjunto a ponto de alguns deles precisarem (...) [da] descoberta dos 'animais de fazenda"'.(idem, p.96)

No Brasil, são poucos os estudos destas temáticas, turismo e lazer, no campo da história. ${ }^{4}$ Cabe fazer uma ressalva, as casas secundárias podem ser incluídas dentro de uma

3 Os estudiosos do turismo fazem distinções entre turismo de natureza, ecoturismo e turismo de aventura. Ver HINTZE, 2008, pp.56-66.

4 Os estudos sobre turismo e lazer se concentram em sua maior parte nas áreas de educação física, geografia e sociologia. Ver ALMEIDA E GUTIERREZ, 2005; PEIXOTO, 2007; GONÇALVES E MELO, 2009; 
ideia de lazer, ou seja, as atividades realizadas durante os tempos livres, tempo de não trabalho. Entretanto, para o campo da história ambiental, mais promissora será investigar o surgimento da 'febre das chácaras' como uma determinada apropriação do natural, é ai que reside o foco de nossa atenção. Alguns estudos realizados por historiadores abordando o turismo, o lazer e algumas de suas práticas, como a vilegiatura, apontam a relação entre tempo livre e tempo de trabalho, como sendo fundamental para a investigação sobre o lazer. No final da década de 1980, Denise Bernuzzi de Sant'Ana, pesquisou a emergência da era do lazer no Brasil no contexto da ditadura militar. Sua preocupação era com o surgimento de saberes e práticas especializadas no tempo livre;

Em meio à paisagem endurecida da ditadura militar dos anos $70,(.$. irrompeu uma proliferação discursiva das vantagens e da importância de determinadas atividades lúdicas, de certos espaços de descanso e de diversão que, gradativa e desigualmente, impôs suas múltiplas vozes e ganhou novos espaços na imprensa, nas discussões institucionais, na fala de políticos e empresários.(SANT'ANA, 1992, p.09)

Para a autora o tempo social é uma categoria central na análise. O tempo vivido, na sociedade industrial e urbanizada, partilhado e segmentado entre tempo livre e tempo de trabalho. No período estudado emergem discursos sobre o tempo livre, tomado como objeto de estudos e intervenções institucionais. Ele pode ser o lugar do perigo, do ócio, ou da salvação social, o lazer: "Nessa perspectiva, o lazer é tratado como a negação do erro, do ócio, ou ainda o 'negócio' capaz de excluí-lo ou de tratá-lo. (...) Por isso, pode-se dizer que a 'organização dos lazeres', da qual fala Dumazedier, implica a produção do lazer enquanto um dispositivo." (idem p. 20). Parecia ser um contrasenso, pois no momento no qual a política econômica da ditadura militar impunha arrocho salarial e aumento da carga horária, aumentava consideravelmente os discursos, ações, instituições e legislação sobre o lazer nas horas livres do trabalhador.

A análise de Sant'Ana, demonstra que muitas das formas utilizadas, pelos trabalhadores e suas associações, no usufruto do tempo livre, como por exemplo, as colônias de férias, constituíram-se como estratégias de controle desse mesmo tempo livre, através da construção discursiva e estabelecimentos de práticas reguladas e reconhecidas como lazer. ${ }^{5}$

5 A produção de discursos de controle sobre os tempos livres do trabalhador, das classes populares em geral, estão em pauta desde o século XIX. Padres, filantropos, médicos, intelectuais, patrões, políticos, etc se esforçaram em uma infinidade de estratégias para transformar o tempo livre em tempo de lazer, um tempo controlado, vigiado e programado. Tanto que, mesmo durante os dois conflitos armados mundiais e com a depressão econômica dos anos de 1920 e 1930, aconteceram reuniões e congressos como o Congresso Internacional dos Tempos Livres de Berlim, em 1936: "Desde a sua criação, a seguir à Primeira Guerra Mundial, o Bureau International du Travail assume a tarefa da organização do lazer dos trabalhadores.(..) A organização do lazer dos trabalhadores é mesmo, durante o período altamente crítico dos anos trinta, apresentada como uma condição de paz social e internacional." (THIESSE, 2001, p.370). Pode-se ver que o controle sobre os tempos livres dos trabalhadores possuía, no período da ditadura militar brasileira (1964-1985), uma larga tradição e acúmulos de saberes. 
Esse lazer, pensado, veiculado, controlado, investimento do governo militar e de instituições ligadas ao empresariado, preocupava-se em salvar o trabalhador do tempo livre, associado ao ócio. Procurava eliminar as possibilidades de uma irrupção de usos do tempo livre, ainda que reduzido por pressão da crise econômica e arrocho salarial, que pudessem se tornar campos de distúrbios e dissonâncias na sociedade industrial e urbanizada que emergia no período. Também é significativo a interpretação das relações entre a irrupção dos 'discursos do lazer' nos anos de 1970 e os projetos de construção um corpo saudável e veloz do trabalhador: "....uma nova imagem do corpo: a da saúde, da juventude, da velocidade e da desconcentração; imagem cujo padrão de beleza estaria sujeito a uma determinada disciplina alimentar, física, lúdica, a certas formas de experimentar o prazer". (idem, p.81).

Aqueles projetos visam um determinado corpo no qual os movimentos, a forma, a plasticidade, as cores, o peso, a idade e a intensidade erótica estariam sobre controle, ou poderiam ser planejados e administrados: "O corpo veloz e saudável, esportivo e alegre, tornou-se o corpo legítimo a ser conquistado via lazer e pela compra de inúmeros produtos industrializados."(idem, p. 100). Surgia a moda do suor, do exercício físico ao ar livre: "Desde o final da década de 60 e, especialmente a partir de 1975, o suor entrou na moda: 'A cidade grande está empurrando o brasileiro para fora de casa - para correr, andar de bicicleta, fazer ginástica. A forma física está em alta.'[ver. Veja, out. 79, n. 578, p. 50)"(idem, p. 80). Matrizes que nas décadas seguintes, amalgamadas a era da ecologia, dariam origem ao turismo ecológico, o turismo de aventura, as práticas de esportes na natureza: raftings, caminhadas, canoagem, rapel, etc. Uma matriz para se entender a movimentação de barcos e lanchas, até mesmo o incremento de pescadores na represa de Capivara, local de expansão dos loteamentos para casas secundárias a partir do final da década de 1980.

A natureza faria parte do esforço em compensar e esvaziar a tensão e conflitos correntes no mundo do trabalho. Uma concepção da 'mente' tranquila surgiria no contato do trabalhador com a natureza. A natureza vista como pacificadora das violências cotidianas e dos conflitos vividos no espaço da produção, no espaço urbano por excelência, seja na grande, na média ou a na pequena cidade. Para os que frequentam as colônias, não importa as condições concretas da população local. A paisagem organizada do campo, as 'imagens estetizadas' do turismo e da vilegiatura escondem, mitificam, sobrepõem-se as reais condições sociais de produção experimentadas pela população local que vivencia, constrói e faz parte da paisagem 'idealizada' do campo, da praia, ou da represa Capivara. ${ }^{6}$

O livro de Haroldo Leitão Camargo, Uma pré-história do turismo no Brasil: recreações aristocráticas e lazeres burgueses (1808-1850),(2007), seria uma história do pré-turismo no

6 Em Alvorada do Sul existem colônias de férias da APUEL - Associação do Pessoal da Universidade Estadual de Londrina; da AFCOHAB - Associação dos Funcionários da Companhia Habitacional de Londrina; da AFML - Associação dos Funcionários do Munícipio de Londrina e do Sindicato dos Metalúrgicos de Londrina e região. Todas essas colônias foram construídas e são mantidas pelos próprios sindicatos e associações. Nelas existem apartamentos; salas de jogos, rampas de barcos, cozinhas, etc. 
Brasil. Segundo Camargo, existiam na primeira metade do século XIX, viagens, lugares de vilegiatura, casas secundárias e fontes termais, mas em si, nenhuma se constituía em um "sistema' e não teriam sido originadas com a finalidade turística: "Portanto, no Brasil do início do século XIX, se existissem condições reais para o turismo, seriam acessíveis para pouquíssimos indivíduos ou grupos familiares que, por sua vez, contavam com os serviços dos seus trabalhadores escravos. Então, como seria possível constituir-se num mercado?"(2007, p.237).

Mas o fundamental na análise de Camargo é que não existia a condição fundamental para a prática do turismo, que era um tempo social percebido e vivido entre o tempo do trabalho e o tempo livre. Assim, como para Denise Sant'Ana, a noção de tempo social permite o estudo do lazer e do turismo no campo da história: "No caso específico pareceu-me que, ao estabelecer a noção de tempo social com a passagem da noção tradicional para aquela das sociedades industriais, seria possível encontrar um nexo entre a história e o turismo."(CAMARGO, 2007, p.11). Considerar o tempo social como uma construção social e perceber, nessa construção, uma grande divisão da vida humana em sociedade: “... o tempo de trabalho e o tempo do não-trabalho. É esse último, o tempo livre, que podemos hoje dedicar ao turismo, que ó usufruto do lazer em viagens e no qual o prazer está presente quaisquer que sejas as motivações". (idem, p. 103). Além disso, as noções de recreação e lazer podem ser percebidas e usadas como sinônimos, mas categoricamente o autor considera que “...recreações aristocráticas não tem qualquer vínculo com a noção social burguesa de lazer, em tempo de não-trabalho." Já o tempo de recreio do aristocrata é fluido e rigorosamente indivisível. Não há possibilidade, portanto de associar o lazer a recreação: "Existe, portanto, sob o ponto de vista estrutural, ou da estrutura psicossocial, uma enorme diferença entre as recreações aristocráticas e os lazeres burgueses."(idem, p. 176).

Percebe-se, assim, que o tempo social é uma categoria central na análise das práticas de turismo. Sem a sua compreensão, isto é, sem a investigação das formas como o tempo social é percebido, regulado e vivenciado pela sociedade contemporânea, ou pelos frequentadores e proprietários das 'chácaras', não será possível chegar a uma explicação histórica desse fenômeno na sua complexidade. É certo que o tempo livre de diversas camadas sociais urbanizadas são usufruídos em muitas e diversas práticas e formas de lazer: passeios, televisão, futebol, etc. Mesmo em atividades que representam, também, trabalho, no cuidado e reforma da casa, do jardim, etc. No entanto, um número significativo, escolhe usufruir de seu tempo livre em atividades e práticas que se configuram na posse ou frequência em casas secundárias a beira represa. Os homens e mulheres que possuem suas propriedades (chácaras) às margens da represa e os que trabalham nessas chácaras estão inseridos no tempo social de maneira diversa; uns vivenciam o tempo de lazer, de não trabalho, quando se encontram em suas casas secundárias, já para os outros, os que trabalham nas casas secundárias, as faxineiras, os zeladores, os jardineiros, os finais de semana, o tempo livre dos proprietários e frequentadores, é tempo de trabalho. 


\section{2 - Natureza, paisagem e casas secundárias}

Do ponto de vista do campo da história, as práticas sociais realizadas nos tempos livres, assim como a própria expansão e separação do tempo livre do tempo do trabalho, são construções históricas. A fruição dos tempos livres nas chácaras de lazer às margens dos lagos artificiais envolve uma determinada construção social sobre a ideia de natureza, a qual transforma alguns lugares, diríamos paisagens, em objetos de desejo. $O$ desafio é revelar o que torna essas paisagens em lugares de desejo, pois consideramos que tal como os lugares turísticos, não há, “... a priori,qualquer elemento que se possa considerar historicamente espaço ou atrativo turístico, (...) Tudo isso é inventado e construído, ou criado social e historicamente." (CAMARGO, 2007, p. 60)

Entretanto, determinados lugares, paisagens transformam-se em objeto de investimentos turísticos ou de contemplação. Esse investimento em determinadas paisagens é resultado de uma composição de sentidos e padrões culturais, valores ideológicos e de consumo: "Esses padrões encontráveis nas ideias e na produção cultural vigentes separam de forma ideal, atendendo a pressupostos ideológicos, as paisagens construídas para a contemplação e o deleite, daquelas referentes ao mundo do trabalho."( idem, p. 88).

As paisagens são artefatos da cultura historicamente determinados, transformando-se com as próprias sociedades que as criam. São compostas de camadas de representações, das quais algumas possuem suas origens a centenas, às vezes, milhares de anos, e outras são tão recentes quanto o presente. (SCHAMA, 1996, GANDY, 2004, CLAVAL, 2004). Assim como os geógrafos, os historiadores ambientais se apropriam da noção de paisagem em seus múltiplos aspectos, pois ela denota diversas formas da relação dos homens com a natureza. Destacamos os aspectos de investimentos de sentimentos e percepções difusas, sonhos e medos presentes na construção das paisagens.

A decisão da escolha do lugar da casa secundária, cujo fenômeno no Brasil parece estar muito associado a 'vilegiatura marinha'(SCHOSSLER, 2010), parece conter, também, uma necessidade de evasão. Expressões como "aqui é sossegado', 'é muito silencioso', 'consigo ouvir os pássaros', 'posso ouvir o vento', 'dá para ouvir a chuva caindo no telhado', mencionadas por proprietários e frequentadores, conduzem a possibilidade de que a escolha possa estar associada a uma 'paisagem sonora', ou a um desejo de vivenciar uma "paisagem sonora" anterior, ou diferente da existente no mundo urbano. (SCHAFER, 1976, LOWENTHAL, 1976). Esse aspecto, revelaria percepções sobre a natureza, como um lugar associado à harmonia, ou pelo menos, contraposto ao mundo da civilização urbana, uma espécie de mito moderno da natureza intocada(DIEGUES, 1996). Desconheceriam, os proprietários e frequentadores das chácaras, as transformações daqueles espaços provocados pela ação humana, como o próprio lago? 
As origens das casas secundárias poderia ser procurada nas práticas das "villas' romanas; ou das mansões da nobreza inglesa dos séculos XVII e XVIII; das casas de campo da burguesia no século XIX. Mas a busca das origens é a maldição da história e poderia se tornar um exercício de anacronismo histórico. Semelhanças aparentes apenas escondem as diferenças existentes entre desejos, origens, classes sociais e escolha de lugares. $O$ fenômeno atual, que pode ser encontrado em praticamente todos os lugares e países, está associado, assim como turismo, à expansão do mundo moderno, urbanizado e industrializado. Faz parte do uso do tempo livre cada vez mais extenso em períodos e camadas sociais. (BOYER, 2003, p. 55)

Este fenômeno está inserido no sistema de turismo, uma re-apropriação da natureza, construindo paisagens de desejo que se tornam mercadorias fictícias. O espaço natural, agora transformado em paisagem de vilegiatura, era há bem pouco tempo terra agrícola, passando a ser usado não mais para produção agrícola mas para a satisfação de sentimentos, como a vilegiatura. Cria-se, assim, um desejo de paisagem, ou a própria paisagem torna-se objeto do desejo de consumo, podendo então ser considerada uma mercadoria fictícia na medida em que não existe, mas é uma criação do mercado.

\section{3 - Periodizações, temporalidades e história ambiental}

A emergência das chacáras de lazer representaria mudanças significativas no processo de co-evolução das relações entre os humanos e a natureza. Nesse sentido, o estabelecimento de periodizações para as mudanças e permanências torna-se um imperativo para a análise do processo. ( LE GOFF 1994). O estabelecimento das temporalidades inerentes às mudanças e permanências significativas envolvem duas categorias de tempo: o tempo histórico e o tempo biológico. A historicidade das transformações ou permanências está relacionada também ao mundo natural que, como entende a história ambiental, mantém relações de coevolução. A história ambiental vem procurando manejar estas duas dimensões do tempo em suas análises, incluindo o tempo histórico, das sociedades humanas, e também reconhecendo a historicidade dos sistemas naturais. "O desafio", como alertou recentemente José Augusto Padua, "é construir uma leitura aberta e interativa da relação entre ambos."(2010, p.97). As correntezas de um rio, as cheias e secas surgiram antes do aparecimento da espécie humana e permaneceram ainda por um largo período sem que as

7 MARTINEZ afirma que na Espanha em 1950 havia 6.370 .354 residências para 182.040 'residências secundária”. Em 2001 havia 20.801.490 domicílios e 3.323.317 residências secundárias. As residências secundárias aumentaram cerca de 20 vezes enquanto as outras apenas 03 vezes no período.(2003, p.55). Estudos sobre as casas secundárias em Portugal indicam motivações e usos diferenciados, como reconstrução de unidades familiares antigas por migrantes, para além das motivações de ruralidades ou amenidades do campo.(ROCA e outros, 2009) 
sociedades conseguissem manejá-las. ${ }^{8}$ Variáveis como espaço, população, tempo, tecnologia e elementos simbólicos constituem-se como condicionantes neste processo de co-evolução. ${ }^{9}$ Uma pequena população, vivendo por um largo período no mesmo espaço, pode provocar transformações equivalentes a uma população maior em menor espaço de tempo. Assim também ocorre com as outras variáveis, como a tecnologia desenvolvida, ou disponível, em cada momento.

A periodização para a febre das chácaras, então, remonta a meados do século 20 , com a expansão da 'era das grandes barragens' e do turismo de massa. O tempo histórico e o tempo biológico se entrecruzam quando o curso de um rio é alterado por uma contenção artificial, como as hidrelétricas, alterando os ritmos das correntezas, das cheias, da qualidade da água e das condições ambientais para a sobrevivência de todas as espécies. Algumas espécies existentes acabam por desaparecer, ou diminuem radicalmente. Além disso, a introdução acidental ou intencional de espécies exóticas cria uma nova 'dinâmica' de competição no mesmo meio. Os ritmos biológicos das espécies são assim alterados pelos tempos históricos dos homens. Por outro lado, o lago cria as condições de outras práticas pelos humanos, como a vilegiatura, ou a casa secundária. O lago é uma dessas criações de paisagens artificiais da era antropocena.

Ao considerar que a febre das chácaras são práticas desenvolvidas na natureza, que são um fenômeno associado às transformações recentes provocadas pelos homens, como a construção de represas e, também, à expansão do ideário ecologista, abre-se a perspectiva de inseri-la como um objeto de estudo da história ambiental. Donald Worster (1991), na bastante citada divisão tri-partite do campo de estudo da história ambiental, considerou que os aspectos simbólicos, o mais intangível dos processos produzidos pelos homens na sua relação com a natureza seria uma dos temas a serem investigados. $\mathrm{O}$ aspecto simbólico tem sido enfatizado por diversos outros historiadores desse campo, como William Cronon, o qual chamou a atenção para o fato de que, por exemplo, o alimento não ser apenas um feixe de calorias e nutrientes, mas ser também um 'constructo social'.(CRONON, 1990, p. 1124)

Essas práticas, em grande parte, possibilitadas pelo usufruto do tempo livre nas sociedades modernas e urbanizadas, mas não necessariamente industrializadas, criam novas paisagens, definem novas formas de apropriação da natureza, instituindo novos territórios e territorialidades ${ }^{10}$. Os lugares que são escolhidos para e pelo turismo, sofrem impactos socio-econômicos de variadas ordens, produzindo conflitos, nem sempre

8 Em setembro do ano de 2009, Johan Rockström(2009), junto com mais 26 cientistas de diversas especialidades, países e instituições de pesquisa, afirmaram que em alguns dos processos químico-fisicos, que aparentemente estariam fora do controle dos humanos, já se notava claramente a ação humana. Talvez, o homem não seja o principal causador das "mudanças globais", mas é um importante fator de mudança das paisagens, especialmente se considerarmos as alterações provocadas nos rios a partir do final do século XIX, com o surgimento da produção de energia elétrica a partir da correnteza fluvial, ou seja, a 'era das grandes barragens."

9 Para discussão metodológica sobre uma perspectiva interdisciplinar e o uso destas variáveis ver DRUMMOND, (2000) 10 Os habitantes da cidade de Alvorada do Sul denominam os proprietários das chácaras como "chacreiros" e os loteamentos de 'nas chácaras' em nítida contraposição a moradores e a cidade. 
explícitos. ${ }^{11}$ Mas a relação entre chacareiros e moradores pode ser de cooperação, como sugere um estudo recente sobre sitiantes no bairro rural de Ribeirão Vermelho, no município de Alvorada do Sul.(MUNHOS, 2007) Em alguns momentos as demandas legais pela 'reserva natural', as exigências e fiscalização por parte da concessionária da hidrelétrica podem criar tensões entre os 'chacareiros', a lei e a empresa. ${ }^{12}$ Os usos do lago também são motivos de conflitos. Para a concessionária, a água é reserva para produção de energia elétrica. Os outros usos e práticas como pesca, vilegiatura, banhos dependem do nível de água. É comum, também, ouvir reclamações quanto a administração do nível do reservatório. São demandas conflituosas em torno da apropriação da natureza.

Os marcos significativos das transformações da natureza na região não se limitam aos cursos dos rios e aos aspectos simbólicos associados ao tempo social, envolvem também a apropriação concreta da natureza, transformada em 'terra', que marcam a constituição atual do espaço no qual se construíram as cidades, as barragens e as chácaras. Em linhas gerais, trata-se do surgimento e expansão da organização espacial centrada no mundo urbano.

No século XIX, as bacias hidrográficas do rio Tibagi e Paranapanema começaram a ser objeto de exploração e disputa por novas formas de ocupação e aproveitamento da natureza, os primórdios da 'grande transformação', conforme Karl Polanyi denominou o processo de transformação da natureza em 'terra', uma mercadoria fictícia. As evidências da transformação são encontradas nas várias expedições organizadas por particulares, como as do Barão de Antonina, e outras de cunho militar durante o período da guerra contra o Paraguai. Na década de 1880, a Comissão Geográfica e Geológica da Província de São Paulo, comandada por Teodoro Sampaio, fez um mapeamento do curso do rio Paranapanema. Esses grupos percorreram, descreveram e mapearam o seu curso e suas margens.

Na primeira metade do século XX, com a denominada a 'marcha do café', suas margens que eram territórios indígenas foram re-ocupadas por colonos brancos, mas ainda continuavam a ser uma área de 'pestilência'. Na foz do rio Tibagi com o Paranapanema surgiu um povoado no início dos anos de 1940, hoje município de Primeiro de Maio.

$11 \mathrm{O}$ Sr Arlindo estimou que 50\% do movimento de seu comércio é proveniente dos proprietários das chácaras. A D. Aparecida considera que o movimento das chácaras 'salvou' a cidade. O Sr. Reginaldo mudou-se para Alvorada em razão da demanda de serviços de mecânica náutica. Ele também informou que no início percebia uma tensão entre os jovens da cidade e os filhos dos proprietários, especialmente em relação as possibilidades de namoro.

12 Foram realizadas entrevistas com moradores da cidade de Alvorada do Sul e também com alguns proprietários de chácaras: Vanderlei Pereira Viana, 45 anos,. Natural de Porecatu-PR, agricultor e desde de 1993 funcionário público municipal. Atualmente também exerce a atividade de zelador de chácaras. Aparecida Giovanineti Pires, natural de Alvorada do Sul, 82 anos, aposentada. Proprietária e moradora na chácara 25 do Balneário Indianápolis, Alvorada do Sul. Arlindo Pereira da Cruz, 45 anos, natural de Alvorada do Sul. Comerciante do ramo de materiais de construção, também proprietário de chácara nas margens da represa; Reginaldo da Silva Pereira, comerciante e mecânico náutico. 37 anos, natural de Ivaiporã. Há dez anos reside em Alvorada do Sul. Valdinei Aparecido Zampolo, 57 anos, natural de Alvorada do Sul. Corretor de imóveis. Foi o Sr. Arlindo que fez denominou a expansão dos números de chácaras como a 'febre das chácaras'. A D.Aparecida mostrou uma 'notificação' da Duke Energy, exigindo a retirada de uma cerca as margens da represa que estaria em desacordo com a legislação. Ela disse que há alguns anos houve uma mobilização contra a ação da Duke Energy. 
Rapidamente tiveram que mudar a localização para outro lugar mais afastado por causa da malária e da febre amarela.

A 'marcha da cafeicultura' significou o momento de aceleração da 'grande transformação' da floresta em terra. O surgimento da cidade de Londrina, atualmente a maior cidade localizada na bacia do Tibagi, no início da década de 1930, está relacionado ao de busca por novas áreas de produção e fornecimento de matéria prima que levou os países centrais a vasculhar o mundo. Neste momento, a partir da segunda metade do século XIX, o imperialismo buscava suas potencialidades de lucro em todo o planeta. (HOBSBAWM, 1988) Esse movimento afetaria a bacia do rio Tibagi e do rio Paranapanema, assim como afetou a cidade de São Paulo, com a expansão da atividade cafeicultora impulsionada pelos novos tempos de ritmo acelerado.(SEVCENKO, 1998)

O que motivou a 'ocupação'13 da bacia foi a terra, aquilo que Donald Worster, seguindo Karl Polanyi, chamou de 'simplificação da natureza'

Todas as forças e interações complexas, seres e processos que designamos como 'natureza' (às vezes até elevada ao status honorífico de uma 'natureza' capitalizada), foram reduzidas a uma simplificada abstração, 'terra'[...]a terra tornou-se 'mercantilizada'; ela veio a ser considerada como se fosse uma mercadoria e, por essa maneira de pensar, foi disponibilizada para ser comercializada sem restrição.(WORSTER, 2003, p.12)

Somente a partir dos anos de 1920 a expansão da cafeicultura atingiu a margem leste do rio Tibagi, embora já tivesse avançado até o espigão que separa os rios Cinza, afluente do Paranapanema, e o Tibagi. Na década de 1930 inicia-se a 'moderna colonização' na margem oeste com o surgimento do núcleo urbano de Ibiporã e depois Londrina. Até a década de 1960, a cafeicultura representava a principal atividade agrícola e econômica desenvolvida na parte baixa da Bacia do Tibagi. Após esse período foi substituída rapidamente pela produção altamente tecnificada da soja, do trigo e do milho.

A cidade de Londrina teve um rápido crescimento populacional. Em meados dos anos de 1940 contava já com aproximadamente 50 mil habitantes. Na década de 1960 sua população ultrapassou os 100 mil habitantes. Nos anos de 1980 atingiu 300 mil e, atualmente, passa dos 500 mil habitantes. A maior parte desse contingente populacional era oriunda das pequenas cidades da região, ou que habitavam a zona rural, cuja estrutura socioagrária fora destruída pela expansão do complexo do agrobusiness. Homens e mulheres que haviam nascido e crescido nas atividades agrícolas, nas quais os tempos de trabalho e descanso não

13 A ideia de ocupação de um território foi criticada como sendo uma versão ideologizada, uma vez que pressupunha que os territórios estavam vazios, sem presença humana. Ver especialmente MOTA(1994) TOMAZI (1997) 
estão, necessariamente, marcados e separados pelo ritmo da produção industrial. Uma vez que os tempos sociais no mundo agrícola, não obedecem à delimitação em dias de semana e finais de semana, mas os ritmos das safras e suas necessidades, a investigação sobre uma possível memória de tempos sociais anteriores poderá fornecer algumas explicações para a expansão das chácaras enquanto fenômeno histórico das relações entre homens e natureza.

A partir da década de 1940 os rios passaram a ser apropriados pela sua capacidade de energia hidráulica, seria o início da 'era das grandes barragens'. A partir dessa década, a febre da eletricidade se instalou nos projetos estatais de desenvolvimento e incorporação das áreas dos interiores. Atualmente ao longo de seu curso existem 08 barragens para a produção de energia elétrica, restando poucos quilômetros do seu curso inalterado. A área coberta pelos lagos dessas barragens cobre aproximadamente mil quilômetros quadrados. A maior delas, a represa de Capivara, construída nos anos de 1970, na região de Porecatu$\mathrm{PR} /$ Taciba/SP, tem um reservatório com mais de $500 \mathrm{~km} 2$ de área alagada. A influência do barramento do curso do rio atinge além de 70 quilômetros a montante e cerca de 50 quilômetros no curso do Rio Tibagi, o principal afluente da margem esquerda do rio. A construção de uma barragem como esta provoca muitas alterações na dinâmica socioambiental da bacia. Inunda milhares de hectares de terra; desloca milhares de moradores; altera a dinâmica da flora e da fauna; extingue e introduz espécies. Cria novas formas de aproveitamento da natureza que havia sido transformada em terra. A barragem de Capivara, representaria assim, um dos marcos significativos da história ambiental dessa bacia hidrográfica, uma das principais transformações que impulsionaram o fenômeno de 're-ocupação' das margens da represa, pelas chácaras. O surgimento da era da ecologia e/ou da ecologização da sociedade; as transformações na estrutura socioagrária e a desumanização do campo; a constituição de uma sociedade urbanizada, com tempos sociais da modernidade, seriam os outros vetores associados que, em nossa hipótese, teriam criado as condições necessárias para a febre das chácaras, como foi mencionado anteriormente.

Por outro lado, a urbanização e o aburguesamento da sociedade brasileira, especialmente nas cidades do interior, evidenciado no surgimento das médias cidades como Londrina (500 mil habitantes) e Maringá (300 mil habitantes), ambas a cerca de 60 quilômetros ao sul do rio Paranapanema, são outros fatores sociais que se somam aos já mencionados que criaram as condições sociais e de sensibilidade para desenvolver as novas práticas junto ao lago: as chácaras de lazer, em loteamentos ou condomínios fechados, os passeios de barcos; as casas secundárias, pousadas, colônias de férias de associações e sindicatos de trabalhadores e instituições. Antigas práticas, como a pesca, são transformadas com as mudanças do ambiente aquático, a introdução de novas espécies de peixes e novos equipamentos.

A natureza, então, re-transformada em uma nova mercadoria, pode ser consumida. Existiria, portanto, um novo marco significativo no processo de co-evolução. Esse novo 
tempo-espaço seria o criado pela prática do turismo, ou da casa secundária. Quaisquer espaços, quaisquer atividades desenvolvidas tornaram-se objeto da valorização enquanto mercadoria. Os espaços usados para usufruir o tempo livre não poderiam ser uma exceção: "Há também o ócio. Com a indústria do ócio o capitalismo apoderou-se dos espaços que ficaram vazios: o mar, a praia, a alta montanha. Criou uma indústria nova, uma das mais poderosas: a indústria do ócio."(LEFÉBVRE, 1974, p. 221 citado por GAMA, idem, p. 20).

Nesse sentido, pode-se, então, estabelecer alguns marcos significativos para a periodização do processo de transformação e apropriação da natureza que estamos investigando: os espaços destinados às casas secundárias, as chácaras de lazer, eram florestas, ocupadas por territórios indígenas até o início do século $\mathrm{XX}$, que foram, em um primeiro momento, transformadas em terra agriculturável, especialmente a partir dos anos trinta do século XX. A construção da barragem, em meados dos anos 70 , representa uma nova forma de apropriação da natureza e, ao mesmo tempo, torna uma parte daquelas terras, com o alagamento, indisponível para a agricultura A legislação ambiental determina que as margens do lago sejam transformadas em área de preservação, dando uma nova forma para a sua utilização. As terras agriculturáveis que haviam sido ocupadas na maior parte pelas pequenas propriedades cafeicultoras, foram incorporadas quase que totalmente, ao sistema do agrobusiness a partir dos anos de setenta. $O$ restante das pequenas propriedades e parte das margens do lago, tornaram-se, após os anos oitenta, terra para loteamentos, transformada pela 'indústria do ócio' em mercadorias para serem consumidas.

As transformações espaciais, ou reorganizações territoriais, e as consequências socioambientais provocadas pela expansão das 'casas secundárias' tem sido a preocupação central de vários estudos que se dedicaram a esse tema no Brasil e em outros lugares. Os estudos demonstram o crescimento em números; a lógica de distribuição espacial; a necessidade de planejamento; na avaliação de seus efeitos 'benéficos', como o reaproveitamento de áreas esvaziadas pelo êxodo rural; o incremento nos negócios e ofertas de emprego, de um lado e, de outro, nos impactos ambientais, na destruição de patrimônios; conflitos com a população local e, mesmo, o desalojamento dessas populações pelos novos ocupantes. (ASSIS, 2003; MARTINEZ, 2003, HALL E MÜLLER, 2004, CRAVIDÃO, 2008). A paisagem da vilegiatura é o resultado de uma específica composição de tempo e espaço, sobrepondo, soterrando e entrando em conflito com as outras composições anteriores e/ou desejadas. São formas, portanto, históricas da relação entre os humanos e a natureza. 


\section{4 - A 'febre' das chácaras: um objeto de pesquisa da história ambiental?}

O surgimento dos loteamentos de chácaras de finais de semana, áreas de turismo, de lazer, que podem ser denominadas de casas secundárias, está sendo considerado, na nossa argumentação, como uma das novas formas de apropriação das margens da represa. Somente em dois municípios da margem paranaense do reservatório, Alvorada do Sul e Primeiro de Maio, com população de cerca de 20.000 habitantes, em levantamento preliminar, o total ultrapassa a casa das duas mil chácaras. Os primeiros loteamentos teriam surgido no final dos anos de 1980 e tendo se ampliado consideravelmente nos anos seguintes. Atualmente encontra-se em desenvolvimento vários projetos de loteamento. Um morador e comerciante da cidade de Alvorada do Sul chamou esse processo de a febre das chácaras. Mas sob o manto do igual, do indiferenciado da febre das chácaras, parece haver uma diversidade de formas, desejos, atores, práticas, sensibilidades e relações sociais concretas que possuem origens, temporalidades e consequências distintas que demandam uma investigação aprofundada e detalhada. (MUNHOS, 2007)

As origens dos loteamentos e características das chácaras quanto as suas formas, como são organizadas, ocupadas e usadas assumem características múltiplas. Podem ser simples loteamentos, com apenas iluminação e a divisão de terrenos ou até condomínios fechados de alto padrão, com toda a estrutura de lazer, ruas asfaltadas, ajardinamento, segurança, portarias, etc. As casas e construções das chácaras também possuem uma grande diversidade: desde casas com centenas de metros quadrados, projetadas por arquitetos renomados, com materiais luxuosos; com trapiches para barcos, lanchas que chegam a custar mais de uma centena de milhar de reais. No outro extremo, pequenas casas com quartos grandes e uma cozinha, com o sistema de propriedade dividido entre vários sócios, pequenos barcos de motor a popa, que são usados de forma alternada, sem ajardinamento, às vezes com pomares de fruta, ou apenas gramados, cercas de fio de arame com farpas. É comum, em épocas de feriados, encontrar barracas de camping anexas à construção. Os proprietários moram em várias cidades da região, com distâncias superiores a cem quilômetros, como a cidade de Apucarana-PR. Alguns residem em outros estados, vindo apenas algumas vezes por ano para suas chácaras. Suas atividades também são diferenciadas: comerciantes e empresários de diversos ramos, como pneus, restaurantes, loja de tecidos; empresários do ramo de transporte, construção civil, imobiliário, mobiliário, indústrias de equipamentos médicos; profissionais liberais, médicos, advogados, contadores; professores; funcionários públicos; militares; operários especializados; prestadores de serviços, como encanadores, mestre de obras, eletricistas e aposentados. A frequência do uso e permanência, em sua maioria, parece ser nos finais de semana e feriados. A proximidade dos locais de moradia permanente facilita o deslocamento semanal. 
Em muitas destas chácaras, principalmente as mais próximas do núcleo urbano, existem moradores fixos, a maior parte aposentados, que se dedicam a hortas, pomares, pescaria, criação de pequenos animais, mas não com finalidade comercial. Alguns tem atividades nas cidades da região, como caminhoneiros, vendedores, etc. Nos finais de semana recebem visitas de parentes, filhos, noras, genros, netos, netas e amigos. A origem e as antigas atividades destes moradores, também como dos proprietários de residência temporária, são muito variadas: metalúrgicos, operários especializados, comerciantes, professores, funcionários públicos, ferroviários, etc. Residiam em diversas cidades da região. Algumas destas 'chácaras de aposentados' são simples, com construções básicas e algumas dependências. Outras assumem características de casas de veraneio, com projetos de arquitetura e ajardinamento, relevando o padrão aquisitivo do morador. As formas de distinções sociais, no mundo burguês, acompanham os sinais da aparência e de práticas. Tipos de casas, jardins, condomínios, barcos revelam a situação social do indivíduo, já que todos passeiam e pescam nas mesmas águas.

Alguns estudos têm sido desenvolvidos, na sua maioria no campo da geografia, indicando a extensão desse fenômeno de apropriação das margens de represas pelas 'casas secundárias', consideradas como atividades de turismo e lazer. Essas pesquisas demonstram com nitidez que a febre das chácaras não é peculiar ou particular ao lago da represa de Capivara. O mesmo movimento pode ser observado em várias barragens construídas em rios de diversas regiões no Brasil. (COBOS, 2003; VIOLANTE, 2006; GARCIA, 2007; LEME, 2007; CALAZANS, 2008 e LARRABURRE, 2009).

As chácaras são um fenômeno associado a processos de transformação e apropriação recentes do espaço e da natureza na região como: o barramento dos rios para produção de energia elétrica; a 'desumanização' do campo após os anos de 1970, decorrente da expansão do complexo do agrobusiness e o aumento da população urbana. Nesse sentido, as chácaras, então, sobrepõem-se às práticas, relações sociais e de produção soterradas por aqueles processos. Surgem novas atividades, atores sociais, relações sociais e de produção, novas paisagens e, obviamente, novos imaginários. (MUNHOS, 2007) As pequenas propriedades, que margeavam os pequenos afluentes do rio Paranapanema, na região de Alvorada do Sul, foram sobrepostas pelo lago em meados da década de 1970 e pelo complexo do agrobusiness. Seus antigos moradores e proprietários foram obrigados a se mudarem para as cidades. $\mathrm{O}$ antigo Bairro da Aguinha, local do sítio do pai de D. Aparecida, hoje está coberto por água e em suas margens as chácaras compõem parte da nova paisagem. 
Imagem 1- Bairro da Aguinha

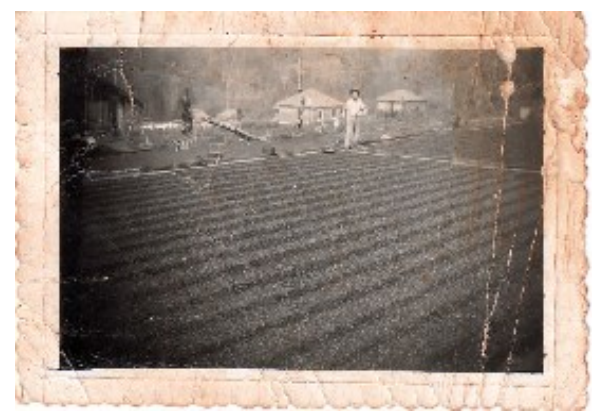

Foto: Acervo pessoal da Sra. Aparecida Giovanineti Pires. ${ }^{14}$

Em seguida, apresenta-se algumas questões que estão sendo investigadas no percurso da pesquisa. Inicialmente percebeu-se que as paisagens surgidas com a represa, as atividades agrícolas do complexo agrobusiness e as chácaras soterraram, mas não eliminaram os conflitos decorrentes do desaparecimentos das paisagens anteriores e, também, a memória que aparece frequentemente nas narrativas. (REIS, CATULLO $\mathrm{E}$ CASTELLS, 2005, p.73, MUNHOS, 2007). Nesse sentido, a continuidade da investigação sobre o que o Sr. Arlindo denominou de a febre das chácaras, deverá considerara análise desses processos subjacentes que propiciaram, ou criaram as condições, para a emergência das casas secundárias, a vilegiatura, o turismo, o lazer. As chácaras seriam, então, destinadas ao gozo do tempo livre, um lugar no qual não imperaria o tempo de trabalho, vivido nas cidades de origens e em suas atividades profissionais.

Deve-se, também, observar como são organizadas e quais práticas seus proprietários desenvolvem durante a permanência nos finais de semana. Munhos menciona um sitiante, o qual diz que os chacareiros trabalham 'feitos doidos' nos finais de semana(2007,p.22). Em muitas das chácaras, os proprietários se dedicam a plantar, carpir, cuidar de hortas, pomares e, às vezes, quando moradores permanentes, a criar pequenos animais domésticos como galinhas, patos, etc. Apresentam aspecto de um 'pequeno sítio', uma pequena propriedade rural. Há também a recuperação de hábitos e práticas associadas ao passado, como fornos e fogões a lenha. Em casas mais recentes, este aspecto estende-se até a decoração com a incorporação de 'móveis rústicos', ou feitos com madeiras de demolição. ${ }^{15}$ Poder-se-ia, então, argumentar que as chácaras representam um retorno ao rural, a reelaboração de memórias da experiência vivida na estrutura socioagrária anterior ao processo de implantação do sistema do agrobusiness?

\footnotetext{
14 Foto do acervo de D. Aparecida, gentilmente cedida para a pesquisa. Ela não soube precisar a data da foto, mas é provável que seja dos anos de 1960. Na foto vê-se seu pai no terreiro de café, as casas de moradia no segundo plano e ao fundo o vale por onde corria a 'Aguinha". O Sr. Arlindo mencionou também várias vezes a propriedade onde nasceu, na "Água da Abobora", que fica nos fundos de sua chácara atual. Disse que uma vez, quando a represa baixou o nível devido a seca, ele e seu pai conseguiram localiza os restos, terreiros e alicerces das casas do sitio.

15 Informações obtidas através das entrevistas mencionadas anteriormente.
} 
As evidências indicam, também, o fenômeno centrípeto, mencionado por Marc Boyer, teria acontecido, somente a partir dos anos de $1960 .{ }^{16}$ Se para a realidade europeia, especialmente francesa, a 'saudade da ruralidade' não faria sentido, talvez faça para os proprietários e frequentadores no caso das chácaras da represa Capivara e de outras chácaras em diversos lugares do país. A 'saudade do campo' é, portanto, uma hipótese a ser examinada como um componente motivador do desejo das 'chácaras', influenciando nos objetos, equipamentos, atividades e práticas que lá são implementadas e desenvolvidas.

Além disso, não sendo a febre das chácaras restrita às margens das represas, por que milhares de pessoas de Londrina, Cambé, Ibiporã, Rolândia, Arapongas, Apucarana, etc, no norte do Estado do Paraná, percorrem até mais de uma centena de quilômetros nos finais de semana, para chegarem até a represa de Capivara? Poder-se-ia associar essa 'febre das chácaras' a expansão do turismo de massa no mundo contemporâneo com suas formas de vilegiatura, contato com a natureza, lugar de descanso e atividades ao ar livre? A urbanização acelerada da região, após a 'modernização conservadora da agricultura' dos anos de 1970, teria alguma relação com a expansão daquelas práticas após os anos de 1980? A urbanização da região teria criado propiciado o surgimento de um tempo social, dividido entre tempo de trabalho e tempo livre, condição para o surgimento das práticas de lazer nas sociedades contemporâneas? Seriam lugares para escapar do 'stress' urbano, uma evasão da sociedade industrial? As chácaras de lazer, ranchos de pesca, 'casas secundárias seriam novas práticas relacionadas aos rios, influenciadas, ou decorrentes, pela era da ecologia? Seriam evidências de novas sensibilidades em relação à natureza?

Às margens da represa de Capivara, no rio Paranapanema, o surgimento das chácaras representa a constituição de uma nova paisagem, uma nova forma de apropriação e relação dos humanos com a natureza. Esse artigo procurou apresentar as bases com as quais está se analisando a emergência da 'febre das chácaras'.

\section{REFERENCIAS}

ALMEIDA, Marco Antonio Betine e GUTIERREZ, Gustavo Luis. O lazer no Brasil: do nacionaldesenvolvimentismo à globalização. Conexões. v. 3, n. 1, 2005. Pp.36-57.

ARRUDA, G. Rios e governos no Estado do Paraná: pontes, "força hydraúlica" e a era das barragens (1853-1940). Varia História, v.24, 39, p.153 - 175, 2008.

16 Quase 40 milhões de brasileiros trocaram o campo pela cidade pequena, e cidade pequena pela grande cidade entre 1960 e 1980. (MELLO, \& NOVAIS, 1998) 
ARRUDA, G. Rios, navegação, ferrovias e a construção do território do Paraná In: A natureza dos rios: história, memória e territórios.1 ed.Curitiba : Ed. UFPR, v.01, p. 85-139. 2008b

ARRUDA, Gilmar. Cidades e sertões: entre a história e a memória. Bauru-SP: Edusc, 2000.

ARRUDA, Gilmar. Descendo o rio: alguns apontamentos para uma história ambiental do rio Tibagi-PR In: FRANCO, José Luis de Andrade e outros. (orgs.) HISTÓRIA AMBIENTAL fronteiras, recursos naturais e conservação da natureza. Rio de Janeiro : Garamond, 2012, v.1, p. 203-224.ASSIS, Lenilton Francisco de . Turismo de segunda residência: a expressão espacial do fenômeno e as possibilidades de análise geográfica. Território, Rio de Janeiro: UFRJ, v. AnoVII, n. 11,12, 13, p. 107-122, 2003.

BARBOSA, Lívia. Garimpo e meio ambiente: águas sagradas e águas profanas. Estudos Históricos. RJ, vol 4, n. 08, 1991. p. 229-243

BOYER, Marc. História do turismo de massa. Bauru-SP: Edusc, 2003

CACOPARDO, Fernando \& ZUPPA, Graciela. Naturaleza, imagen y sociedad. Mar del Plata y la conquista de la playa. In: ARRUDA, Gilmar (org.). Natureza, fronteira e territórios: imagens e narrativas. Londrina: Eduel, 2005.

CALAZANS, Nelsi Coelho Araújo. A dinâmica sócio-espacial na orla do rio Paraná e o ordenamento do território pelo turismo: a estância turística de Santa Fé do Sul/SP. Aquidauna-MS, mimeo(UFMS- Dis de mestrado em Geografia), 2008.

CAMARGO, Haroldo Leitão. Uma pré-história do turismo no Brasil: recreações aristocráticas e lazeres burgueses (1808-1850). S. Paulo: Ed. ALEPH, 2007.

CLAVAL, Paul. A paisagem dos geógrafos. In: CORREA, Roberto Lobato e ROSENDAAHL, Zeny. (orgs.) Paisagens, textos e identidades. Rio de Janeiro: Eduerj, 2004. pp. 13-74.

COBOS, Valdir José. As atividades turísticas e recreativas e o processo de transformação espacial em lagos artificiais de represas hidrelétricas: o caso dos lagos de Salto Osório e Salto Santiago no rio Iguaçu-PR. Itajai-SC: mimeo(Univile -Dis. mestrado em Turismo e Hotelaria), 2003.

CORBAIN, A. O território do vazio; a praia e o imaginário ocidental. SP: Cia das Letras, 1989

CORBIN, Alan. (org.). História dos tempos livres: o advento do lazer. Lisboa: Editorial Teorema, 2001.

CRAVIDÃO, Fernanda Delgado. Residência secundária e espaço rural. Duas aldeias na Serra Lousã: Casal Novo e Talasnal. In: SANTOS, Norberto Pinto, GAMA, Antonio. (coord.) Lazer: da 
libertação do tempo à conquista das práticas. Coimbra: Imprensa da Universidade de Coimbra, 2008.

CRONON, William. Modes of Prophecy and Production: Placing Nature. The Journal of American History, Vol. 76, No. 4 (Mar., 1990), pp. 1122-1131.

CSERGO, Julia. Extensão e mutação do lazer citadino, Paris século XIX-início do século XX. In: CORBIN, Alan. (org.). História dos tempos livres: o advento do lazer. Lisboa: Editorial Teorema, 2001. Pp. 137-201.

DIEGUES, Antonio Carlos. $O$ mito moderno da natureza intocada. São Paulo: Hucitec, 1996. Disponível em: http://www.apdr.pt/congresso/2009/pdf/Sessão/2025/161A.pdf

DRUMMOND, José Augusto. Ciência socioambiental: notas sobre uma abordagem necessariamente eclética. In: Rivail Carvalho Rolim, Sandra Araújo Pellegrini e Reginaldo Dias(orgs). História, espaço e meio ambiente. Maringá: Anpuh/PR, 2000.

ENZENBERGER, Hans Magnus. Com raiva e paciência: ensaios sobre literatura, política e colonialismo. Rio de Janeiro: Paz e Terra, 1985.

GAMA, Antonio. Notas para uma geografia doa tempo livre. In: SANTOS, Norberto Pinto, GAMA, Antonio. (coord.) Lazer: da libertação do tempo à conquista das práticas. Coimbra: Imprensa da Universidade de Coimbra, 2008.

GANDY, Mathew. Paisagem, estética e ideologia. In: CORREA, Roberto Lobato e ROSENDAAHL, Zeny. (orgs.) Paisagens, textos e identidades. Rio de Janeiro: Eduerj, 2004. pp. $75-91$.

GARCIA, Rita Maria de Paula. Análise da dinâmica sócio-espacial de uma área ribeirinha: um estudo das residências secundárias do rio Sucuriú em Três Lagoas-MS. Aquidauna-MS: mimeo(Dis. Mestrado em Geografia-UFMS), 2007.

GONÇALVES, Cleber Augusto e MELO, Victor Andrade de. Lazer e urbanização no Brasil: notas de uma história recente (décadas de 1950/1970). Movimento. V.15, n3.p.249-271.

HINTZE, Helio Cesar. Ecoturismo na cultura de consumo: possibilidade de educação ambiental ou espetáculo? Piracicaba-SP: mimeo(Dis. Mestrado Ecologia aplicada - USP), 2008.

HOBSBAWM, Eric J. A era dos Impérios. Rio de Janeiro, Paz e Terra, 1988.

LARRABURE, Sara Pugliesi. O fenômeno da segunda residência: o caso do rio Grande entre os estados de São Paulo e Minas Gerais. GEOUSP - Espaço e Tempo, São Paulo, Edição Especial, 2009. pp. 93 - 105. 
LE GOFF, Jacques. História e memória. $3^{\text {a }}$ ed. Campinas: Edunicamp. 1994.

LEME, Fernanda Beraldo Maciel. As represas como lugares turísticos: novas significações e valorizações de uma paisagem sem memória. Cultur: Revista de Cultura e Turismo. IlheusBA. Universidade Estadual de Santa Cruz/Programa de Mestrado em Cultura e Turismo. Ano I, no 01, 2007.

LOWENTAL, David. Em busca del sonidos perdidos: Se puede recuperar el paisage sonoro de nuestros antepasados? El correo de la Unesco. Paris: Unesco, noviembre de 1976, ano XXIX, pp.09-15.

MARTÍNEZ, José $\mathrm{M}^{\mathrm{a}}$. Serrano. Las viviendas de segunda residência En la sociedad del «bienestar».El caso de un país turístico: España. Cuadernos de Turismo. Murcia: Universidad de Murcia. 2003, 12; pp. 53-75.

MARTINS, Pedro Alexandre Guerreiro. Contributos para uma história do ir a praia em Portugal. Lisboa: mimeo( Dis. Mestrado - História Contemporânea- UNL), 2011.

MCCORMICK, John. Rumo ao Paraíso: A História do Movimento Ambientalista. Rio de Janeiro: Relume-Dumará, 1992.

MELLO, João Cardoso de \& NOVAIS, Fernando. Capitalismo tardio e sociabilidade moderna. In: SCWARCZ, Lilia Moritz.(org) História da Vida privada. São Paulo: Cia das Letras, 1998. V. 4, pp. 559-659.

MUNHOS, Paula Daniela. Sitiantes e chacareiros do ribeirão vermelho, Alvorada do sul - Pr: sociabilidade, disputas e transformações de um bairro rural. Rio de Janeiro: mimeo (Dis. Mestrado em Ciências Sociais-UFRRJ), 2007.

PÁDUA, José Augusto. As bases teóricas da história ambiental. Estudos Avançados. v.24, $\mathrm{n}^{\circ} 68$, janeiro/2010.

PÁDUA, José Augusto. Um sopro de destruição: pensamento político e crítica ambiental no Brasil escravista (1768-1888). RJ: Jorge Zahar Ed. 2002.

PEIXOTO, Elza. Levantamento do estado da arte nos estudos do lazer: (brasil) séculos xx e xxi - alguns apontamentos. Educ. Soc., Campinas, vol. 28, n. 99, p. 561-586, maio/ago. 2007.

PORTER, Roy. Os ingleses e o lazer. In: CORBIN, Alan. (org.). História dos tempos livres: o advento do lazer. Lisboa: Editorial Teorema, 2001.pp. 19-57.

RAUCH, André. As férias e a natureza revisitada (1830-1939). In: CORBIN, Alan. (org.). História dos tempos livres: o advento do lazer. Lisboa: Editorial Teorema, 2001.pp. 91-135. 
REIS, Maria José, CATULLO, María Rosa e CASTELLS, Alicia N. Gonzalez de. Ruptura e continuidade com o passado: bens patrimoniais e turismo em duas cidades relocalizadas. Cuadernos de Antropología Social. Buenos Aires: Un. de Buenos Aires. N²1, pp. 71-89, 2005. Pp.71-89.

RICHES, Jean-Claude, STRAUSS, Léon. Um tempo novo para os operários: as férias pagas (1930-1960). In: CORBIN, Alan. (org.). História dos tempos livres: o advento do lazer. Lisboa: Editorial Teorema, 2001.pp. 455-504.

ROCA, Maria de Nazaré e outros. Expansão das segundas residências em Portugal. In: $1^{\circ}$ Congresso de Desenvolvimento Regional de Cabo Verde. Cabo Verde, setembro/2009. Universidade Jean Piaget.

ROCKSTRÖM, J. et all. 2009. A safe operating space for humanity. Nature, vol. 461, 24

SANT'ANA, Denise Bernuzzi de. O prazer justificado: História e Lazer (S.Paulo, 1969/1979). São Paulo: Marco Zero/CNPq, 1992

SCHAFER, R. Murray. El mundo del sonido. Os sonidos del mundo. El correo de la Unesco. Paris: Unesco, noviembre de 1976, ano XXIX, pp.04-09.

SCHAMA, Simon. Paisagem e Memória. São Paulo: Cia das Letras, 1996.

SCHOSSLER, Joana Carolina. “ Nossas Praias": Os Primórdios Da Vilegiatura Marítima No Rio Grande Do Sul (1900 - 1950). Porto Alegre: mimeo(Dis. Mestrado em História - PUC-RS), 2010.

SERRANO, Célia Maria de Toledo. Uma introdução à discussão sobre turismo, cultura e ambiente. In: SERRANO, Célia M. Toledo e BRUHNS, Heloisa T. (orgs). Viagens à natureza: turismo, cultura e ambiente. SP; Papirus, 1997

SEVCENKO, Nicolau. Introdução. O prelúdio republicano, astúcias da ordem e ilusões do progresso. In: NOVAIS, Fernando(coord.) História da vida privada no Brasil. República: da Belle Époque ‘a Era do Rádio. São Paulo: Cia. Das Letras, 1998. Pp. 7-48.

SILVA, Telma Domingues da. O ambiente e o turista: uma abordagem discursiva. In: SERRANO, Célia M. Toledo e BRUHNS, Heloisa T. (orgs). Viagens à natureza: turismo, cultura e ambiente. SP; Papirus, 1997

THIESSE, Anne-Marie. Organização dos lazeres dos trabalhadores e tempos roubados (18801930). In: CORBIN, Alan. (org.). História dos tempos livres: o advento do lazer. Lisboa: Editorial Teorema, 2001. Pp. 363-391.

THOMAZ, Keith. O homem e o mundo natural. São Paulo: Cia das Letras, 1988. 


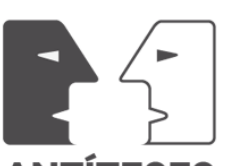

ANTÍTESES

VIOLANTE, Adriano de Cerqueira. Moradores e turistas no município de Porto Rico-PR: percepção ambiental no contexto de mudanças Ecológicas. Maringá-PR: mimeo( UEM-Dis. mestrado em ecologia de Ambientes Aquáticos Continentais), 2006.

WILLIAMS, Raymond. O campo e a cidade. São Paulo: Cia das Letras. 1990.

WORSTER Donald. Para fazer história ambiental. Estudos Históricos, Rio de Janeiro, vol. 4, n. 8, 1991, p. 198-215.

WORSTER, Donald Nature's economy: a history of ecological ideas. New York: Cambridge University Press, 1996. $2^{\text {a }}$ ed.

WORSTER, Donald. Transformações da terra: para uma perspectiva agroecológica na história. Ambiente\& sociedade. Campinas, 5, no.2, 2003. 